\title{
Narrar la propia biografía después de un divorcio. Notas de un estudio cualitativo de interés para la demografía*
}

\section{Tell his/her biography after a divorce. Useful notes of a qualitative study for the demography}

\author{
Montse Solsona i Pairó ${ }^{* *}$
}

\section{INTRODUCCIÓN}

En este artículo presento los resultados de un estudio cualitativo realizado en España sobre las biografías familiares de hombres y mujeres que han vivido la ruptura de una unión en la que hubo hijos. Dicho estudio forma parte del proyecto "Trayectorias familiares después del divorcio. Género, parentesco y territorio" del equipo de investigación sobre el divorcio del Centre d'Estudis Demogràfics ${ }^{1}$. Tal como el título sugiere, entre nuestros objetivos está construir una geografía europea de las trayectorias familiares post divorcio, desde

* Este trabajo debe considerarse producto de los proyectos "Trayectorias familiares después del divorcio. Género, parentesco y territorio" (Ref. SEJ2005-03764/GEOG) y "Familias reconstituidas y equidad de género: nuevas paradojas" (Ref. CSO2008-00654) subvencionados por el Plan Nacional I+D+i del Ministerio de Educación y Ciencia.

** Universitat Autònoma de Barcelona, Departamento de Geografía, msolsona@ced.uab.es

${ }^{1}$ La socióloga Cristina Brullet, ha sido mi asesora en todo el proceso. Con mis colegas de equipo, los demógrafos Carles Simó, Jeroen Spijker y Rocío Treviño, he mantenido discusiones ricas y útiles. La demógrafa Laia Ferrer, técnica del proyecto, ha realizado imprescindibles tareas de transcripción y codificación de las entrevistas. Con los otros compañeros de equipo (Muriel Casals, Iñaki Permanyer y John MacInnes) hemos hecho un trecho de camino juntos. ¡Gracias por todo! 
la perspectiva de género ${ }^{2}$. Por ello, apelando a la metodología cuantitativa, estamos elaborando un atlas del divorcio y el post-divorcio en Europa ${ }^{3}$, combinando datos europeos censales (estocs de divorciados); del movimiento natural de la población (flujos de matrimonios, divorcios y segundas nupcias); y encuestas biográficas con una precisa datación de los acontecimientos, para estimar la intensidad y el calendario de las transiciones familiares postdivorcio (nuevas relaciones de pareja y filiación) y explorar los factores determinantes, tal como ya hemos hecho anteriormente en el estudio de los factores determinantes del divorcio ${ }^{4}$.

Por otra parte, el estudio cualitativo que presento aquí, cuyo trabajo de campo se realizó en la primavera de 2008 en España, tiene por objeto estudiar los procesos de ruptura de unión a partir de los hechos y las percepciones biográficas, que emanan de las narraciones de los propios protagonistas. Los hechos hacen referencia a la constitución de la unión, el nacimiento de los hijos, la ruptura de la unión, y las nuevas uniones y fecundidades después de la ruptura. Las percepciones biográficas hablan del significado que las personas atribuyen a la ruptura de la unión en su biografía familiar (y otras biografías relacionadas) y de los elementos que intervienen en la redefinición de las relaciones de parentesco que todo divorcio ${ }^{5}$ comporta. Todo ello en un contexto en el que no existen unas normas sociales establecidas respecto a cómo preservar (o no) los vínculos familiares (biológicos o derivados de los biológicos) nacidos de la existencia de hijos antes de la ruptura de una unión 6 .

La metodología etnográfica elegida se ha implementado realizando entrevistas en profundidad a 13 hombres y a 13 mujeres de una generación, grupo social y situación familiar bien determinadas (nacidos en torno a 1955, clase media, y con hijos de la unión que se rompe) y se les ha invitado a narrar su propia historia familiar formulando únicamente cinco preguntas muy generales acerca de: 1) la propia familia, 2) el proceso de ruptura de unión, 3) la trayectoria post-divorcio, 4) la situación actual y las asignaturas pendientes y 5)

\footnotetext{
2 Ver Solsona et al. (2007) para un revisión de la literatura demográfica al respecto.

3 Simó, Spijker y Solsona (2009).

${ }^{4}$ Ver Houle et al. (1999), Treviño et al. (2000), Simó y Solsona (2003), Houle et al. (2006), Solsona y Simó (2007).

${ }^{5}$ Aquí utilizo el término de divorcio o ruptura, indistintamente, para referirme a ruptura de un matrimonio y de una unión consensual, tal como es habitual en la literatura demográfica.

${ }^{6}$ Según la Estadística de Nulidades, Separaciones y Divorcios del Instituto Nacional de Estadística, para el año 2007, un 52\% de los matrimonios disueltos legalmente en España tenían hijos menores de edad.
} 
las diferencias de género percibidas en estos procesos. Las narraciones de nuestros biógrafos y biógrafas permiten conocer en qué medida el divorcio es un punto de inflexión en sus biografías y discutir a fondo el significado mutante de la familia y los vínculos afectivos en la llamada moderna sociedad líquida en términos de Zygmunt Bauman (2003).

Como resultados más destacados cabe mencionar la gran utilidad de este estudio cualitativo para establecer con más precisión qué tipo de conocimiento nos ofrece la aproximación cuantitativa y matizar conceptos a los que con demasiada frecuencia, en los estudios demográficos, se les atribuye una naturaleza estática, cuando en realidad, en caso de divorcio, en este universo de relaciones afectivas, lo único cierto es la permanente mutación. Tal es el caso del propio concepto de familia y las fronteras (borrosas) entre la familia, el hogar, el amor y la sexualidad; y la datación de la ruptura de la unión y los factores determinantes de la ruptura. Todo ello permite entender mejor, por ejemplo, la coexistencia de un hogar reducido (unipersonal o monoparental) con una familia muy amplia, que incluye parientes de sangre, políticos y de adopción; conocer las causas por las cuales, las nuevas relaciones amorosas estables, no se traducen necesariamente en relaciones de convivencia; aprender tanto o más sobre el matrimonio, que de la propia ruptura; y palpar la vulnerabilidad latente en todos los seres humanos, a partir de vivencias que contradicen los roles de género esperados, en cuanto a fortaleza y vulnerabilidad, en una situación crítica -la ruptura de una unión con hijos- que todos nuestros biógrafos consideran como un punto de inflexión en sus biografías, el momento más difícil de sus vidas.

\section{LA METOdOLOGÍA BIOGRÁFICA-ETNOGRÁFICA DISEÑADA}

La metodología utilizada es deudora de las encuestas demográficas biográficas, diseñadas en diferentes países desde principios de los años ochenta, para aplicar métodos estadísticos especialmente diseñados para el análisis demográfico ${ }^{7}$. En estas encuestas, a menudo se recaba información acerca de biografías determinadas, como la biografía laboral, educativa, familiar y residencial ${ }^{8}$. En nuestro caso, se toma como columna vertebral la biografía fami-

${ }^{7}$ Los principios del análisis demográfico de las biografías se presentan con mucha claridad en el libro ya clásico de Courgeau, D. y Lelievre, E. (1989).

${ }^{8}$ La encuesta pionera de 1981 del INED (Institut National d'Études Démographiques), conocida como la 3B, se centraba en tres biografías: familiar, profesional y migratoria (Courgeau, 
liar y se deja a los entrevistados que seleccionen los acontecimientos más importantes de su vida y aquellos que dan sentido a la historia que ellos mismos van construyendo en torno a la constitución de la unión, el nacimiento de los hijos, y el proceso de ruptura y pos-ruptura.

El modelo temático ${ }^{9}$ de esta investigación comprende dos ejes analíticos centrales: familia y género, y cada uno de ellos comprende diferentes niveles conceptuales que quedan recogidos en las siguientes preguntas:

1) Familia: ¿Cómo perciben su familia nuestros biógrafos/as? ¿Quién forma parte de su familia? ¿Vínculos afectivos y relaciones familiares son conceptos asociados? ¿Cómo se nombran los vínculos afectivos después de una ruptura de unión? ¿Qué vínculos son líquidos y cuáles no? ¿Después de la ruptura qué papel cumplen las nuevas uniones y las nuevas relaciones de filiación en la satisfacción de las necesidades afectivas (y sexuales)? ¿Cómo encajan los nuevos vínculos afectivos con los establecidos con anterioridad a la ruptura de la unión?

2) Género: ¿Cómo han vivido los hombres y las mujeres el proceso del divorcio? ¿Los factores determinantes de la ruptura son diferentes para hombres y mujeres? ¿Resulta fácil llevar a cabo tal decisión? ¿Cuáles son las pérdidas y ganancias de la ruptura de la unión para unos y otros? ¿Cuál es el grado de empoderamiento de los hombres y las mujeres en el proceso de ruptura y en la biografía posterior? En los desarrollos post: ¿Cómo se redefine la maternidad y la paternidad respecto a los hijos previos: son ellas imprescindibles y ellos prescindibles? ¿En un período postruptura hombres y mujeres se plantean retos específicos? ¿Cuáles son las asignaturas pendientes en cada caso? Y finalmente, pero no menos importante: ¿La percepción de los divorciados respecto a los patrones de género en el post-ruptura coincide con las regularidades estadísticas?

\section{La muestra: en función de la trayectoria pre-divorcio}

En esta investigación, para la confección de la muestra, se ha optado por establecer la existencia de hijos antes de la ruptura de la unión como denominador común, para tener un escenario homogéneo en el momento de la rup-

1985). La Encuesta Sociodemográfica, implementada por el INE en España en 1991, añadió la cuarta biografía: la educativa.

${ }^{9}$ Para una explicación amplia del concepto de modelo temático ver Bry y Antoine (2004). 
tura, del cual pueden emerger múltiples trayectorias post, y por entender que la redefinición de los vínculos familiares es mucho más compleja cuando ha habido hijos en uniones anteriores.

No se ha establecido ninguna condición respecto a cuál ha sido esta trayectoria familiar post-ruptura (nuevas uniones, nuevas maternidades y paternidades), ni respecto a la edad de los hijos (de infantes a adultos jóvenes), ni al tipo de unión (matrimonio o cohabitación). Sin embargo, para evitar intervenir en momentos demasiado sensibles de las biografías de ruptura, se ha puesto como condición que la ruptura de la unión hubiera acontecido entre 3 y 15 años antes del momento de la entrevista. Asimismo, se ha elegido entrevistar a personas pertenecientes a las generaciones nacidas en torno a $1955^{10}$, casi pioneras del divorcio en España, que registran el mayor porcentaje de población divorciada en los últimos censos; por la misma razón, el trabajo de campo se ha realizado en diversas áreas metropolitanas de España (Barcelona, Madrid, Valencia y Sevilla), dónde la incidencia del divorcio es mayor (Solsona y Simó, 2007).

De forma expresa, y por querer centrar el estudio en los aspectos relacionales, más que en los aspectos materiales, se ha buscado que los entrevistados pertenecieran a un grupo social homogéneo en cuanto a nivel educativo y condición económica, por lo cual la mayoría de los entrevistados tiene estudios universitarios y desarrollan su actividad profesional en el ámbito de la cultura y los negocios. Son asalariados o profesionales liberales en ramas de actividad diversas del sector terciario (arquitectura, arte, gestión de empresas, docencia, investigación, editorial, administración pública, etc.).

Finalmente, después de una etapa previa en la que se realizaron 4 entrevistas piloto ( 2 mujeres y 2 hombres en la primavera de 2007) para poner a prueba un guión mínimo para orientar la dinámica de la entrevista, se realizaron 26 entrevistas (realizadas a 13 hombres y a 13 mujeres, sin ninguna relación entre ellos), de una duración aproximada de dos horas, durante la primavera de 2008. Todas las personas entrevistadas cumplen con los requisitos definidos más arriba.

\section{La entrevista: un monólogo y más de un dibujo}

Para el trabajo de campo la metodología utilizada es etnográfica. Es decir, es un estudio directo de las personas que han vivido una ruptura de unión

\footnotetext{
10 Son personas nacidas entre el 1 de enero de 1948 y el 31 de diciembre 1968 (es decir tenían entre 40 i 60 años de edad en el momento de la entrevista). 
mediante entrevistas en profundidad mínimamente estructuradas, para comprender los significados que el propio biógrafo atribuye a los hechos seleccionados de su biografía, y en particular de la forma en que percibe sus vínculos familiares y afectivos.

Esta metodología etnográfica se implementa adoptando un enfoque biográfico, de manera que el entrevistado (el actor o la actriz principal) selecciona las secuencias más significativas de su curso de vida, como si se tratara de un montaje fotográfico, siguiendo el hilo de unas pocas preguntas que impulsan un monólogo pausado en torno al proceso de ruptura, las experiencias afectivas después de la ruptura, y todos aquellos hechos biográficos que dan sentido a los episodios seleccionados. Nuestros biógrafos y biógrafas hablan de su historia familiar a partir de un guión básico con sólo cinco preguntas, de las cuales cuelgan varias muletas a las que únicamente se recorre para garantizar un cuerpo temático común a todas las entrevistas. Las cinco preguntas son las siguientes:

1. Háblame de tu familia

2. Háblame de cómo viviste tu proceso de ruptura

3. ¿Cómo te ha ido después de la ruptura?

4. ¿Cómo vives tu situación actual?

5. ¿Crees que los hombres y las mujeres siguen caminos diferentes después de una ruptura?

La intervención oral de la entrevistadora es mínima, en el rol de escucha consciente, ni siquiera pide explicaciones acerca de lo relatado; su papel prácticamente se limita a sugerir algunos temas y a construir un material gráfico sobre su genealogía y su curso de vida mientras la persona entrevistada (re)construye su historia, un material que como se verá enseguida, bien puede utilizar la persona entrevistada para dar coherencia a su narración.

Se inicia la entrevista explicando el objetivo del estudio, para que la persona entrevistada guarde en algún lugar de su mente la razón por la cual ha sido seleccionada y el foco central de nuestra investigación: la reconstrucción de las trayectorias familiares después de una ruptura. Se inicia la conversación solicitando a la persona entrevistada: "Háblame de tu propia familia". En prácticamente todos los casos la respuesta es "¿qué familia?, ¿la de origen? ¿La que yo he creado?", momento en el cual el entrevistado se da cuenta de que la pregunta no tiene una respuesta estándar predeterminada y comienza a narrarse su propia biografía. La entrevistadora, se limita a escuchar y a dibujar en el cuaderno de campo las figuras correspondientes a la más o menos compleja configuración y constelación familiar (ver una versión simplificada en 
las figuras 1 y 2), anotando el sexo, el tipo de vínculo con ego y la forma de nombrar cada vínculo afectivo o familiar, si es que este nombramiento se produce. Y si es necesario se recurre a la siguiente muleta: ¿hay otras personas con las que tienes lazos emocionales fuertes y que puedes considerar como tu familia?

El dibujo del diagrama de las relaciones de parentesco y vínculos afectivos, que se inicia con la respuesta a la primera pregunta (háblame de tu familia), se va completando a lo largo de la entrevista, hasta constituir la configuración familiar auto-percibida de cada persona entrevistada.

Cuando un silencio prolongado sugiere que la persona entrevistada da por terminada la primera respuesta, se la invita a datar los hechos más importantes de la unión y su posterior proceso de ruptura, a fin de dibujar una línea de vida ${ }^{11}$ que reúna todos los acontecimientos significativos de su biografía familiar (unión, matrimonio, nacimiento de los hijos, ruptura, nueva unión,...). La visualización gráfica de su propia biografía, a menudo conduce al narrador a evocar otros acontecimientos cruciales de su existencia, pertenecientes a etapas de su vida alejadas al momento de la entrevista (acaso a la infancia) y también a diferentes dimensiones vitales. Para mejor comprensión del procedimiento véase la figura 3, en la que se ilustra un ejemplo concreto. Los hechos correspondientes a la biografía familiar son anotados en la línea de vida principal. Ahora bien, cuando un aspecto en particular toma una importancia especial, se dibuja en paralelo una nueva línea para la biografía correspondiente: las biografías de los propios hijos, la biografía de la ex-pareja, los cambios de vivienda, la laboral, la educativa, etc. Así, a lo largo de la entrevista, en un tiempo y lugar determinado, el entrevistado construye una narración retrospectiva única, delimitando a veces, diferentes etapas de su vida.

Con la pregunta 2, "Háblame de cómo viviste tu proceso de ruptura", se pretende conocer la percepción de ego respecto al proceso de ruptura apelando al grado de empoderamiento en la toma de decisiones y a la ruptura efectiva de los vínculos afectivos, teniendo en cuenta el sentimiento de ganancia y de pérdida asociado a dicha ruptura. Ejemplos de algunas muletas utilizadas en esta segunda pregunta son los siguientes: háblame de cómo tomaste

${ }^{11}$ Como las líneas de vida que los demógrafos dibujamos en los diagramas de Lexis, identificando la triple referencia temporal (edad, año del calendario y generación) de los acontecimientos, pero aquí en trazado horizontal, con inicio en el año de nacimiento a la edad cero, y final en algún momento de la primavera del año 2008, o lo que es lo mismo: a la edad actual de la persona entrevistada. 
tus decisiones: ¿sola, mediatizada por la intervención de alguien?; ¿cómo reaccionaron tus hijos e hijas, otros parientes, amigos y las personas más cercanas?; ¿ fue muy largo el proceso de ruptura y de duelo hasta sentir que los vínculos se habían roto del todo y un nuevo espacio se creaba?

Con la tercera pregunta, "¿Cómo te ha ido después de la ruptura?", se quiere conocer el encaje entre las nuevas relaciones familiares y afectivas con las habidas antes de la ruptura, utilizando si es preciso las siguientes muletas: ¿Cómo quedaron tus necesidades afectivas, de ternura, de relaciones amorosas y tus relaciones sexuales? ¿En la construcción de una nueva pareja, qué requisitos pedías/pides para una nueva convivencia? ¿Qué relaciones se han establecido entre tu y tu ex -pareja?

Con la cuarta pregunta se formula una cuestión general, "¿cómo vives tu situación actual? ¿Cuál es tu asignatura pendiente?". También en este caso las respuestas hacen referencia a las relaciones afectivas y familiares más que a otras cuestiones.

Por último, la quinta pregunta se buscaba refrendar o rechazar las regularidades estadísticas respecto al patrón de género de las trayectorias post divorcio $^{12}$, pero lo cierto es que nuestros biógrafos y biógrafas no han querido, prácticamente en ningún caso darnos la razón en general, y si nos han aportado muchos elementos de la diversidad de las trayectorias post divorcio, con independencia del hecho de ser hombre o mujer.

Para finalizar, para cerrar su narración sobre experiencias muy sensibles de sus vidas, de una forma suave y lúdica, pedimos a las personas entrevistadas asociar determinadas palabras (sobre conceptos fundamentales de su monólogo en voz alta: amor, sexualidad, vínculo afectivo, estar en casa, hijos, padres, etc.) con colores, formas y músicas. En verdad, este recurso inicialmente no estaba previsto, pero ya en las primeras entrevistas de prueba advertí, que de alguna forma, una cierta memoria celular se despertaba y dolía. Creo que esta fue una buena idea.

En suma, durante la entrevista, en paralelo con las cinco preguntas básicas utilizamos tres recursos adicionales: 1) diagrama de las relaciones de parentesco y vínculos afectivos, 2) líneas de vida de las biografías múltiples, y 3) Juego de palabras.

12 Dichas regularidades hacen referencia a la mayor propensión de los hombres a contraer una nueva unión matrimonial y a tener hijos de esta unión. Carles Simó y Jeroen Spijker (2009) encuentran este patrón en la nupcialidad en España, Austria, Finlandia, Francia, Alemania y la República Checa; pero en Bélgica, Noruega y Estonia no hay diferencia de género. 


\section{Cómo analizar un universo de constelaciones familiares y biografías múltiples}

En estas entrevistas semi-estructuradas se han recogido dos tipos de información: los hechos y las interpretaciones. En las percepciones del entrevistado impresas en el diagrama de relaciones de parentesco y vínculos afectivos, determinamos la composición del hogar en el momento de la entrevista, los miembros que forman su propia familia, la o las relaciones de pareja, y otros vínculos sentimentales y de amistad, en una configuración global de su mundo de afectos, que incluye tanto a familiares como a no familiares.

En las líneas de vida, tomando como punto de referencia la ruptura de la unión, se recogen los acontecimientos (hechos) significativos de la biografía familiar de cada entrevistado: la emancipación familiar, el noviazgo, relaciones de pareja, la constitución de la unión, nacimiento de los hijos, ruptura de la unión, constitución de nuevas uniones (sexuales, sentimentales, de convivencia o no, matrimonios), nuevos hijos, si los hubiere, etc. En general se trata de hechos, pero a veces la frontera entre los hechos y las percepciones no es fácil de delimitar, o mejor dicho, los mismos hechos pueden dar lugar a distintas percepciones. Por ejemplo, en una relación sentimental o sexual, cada persona implicada puede tener su propia percepción respecto al tipo de vínculo que se está creando: relación estable, esporádica, etc.

Las interpretaciones, el sentido que el biógrafo da a los acontecimientos vividos provienen de las propias narraciones. Así, para proceder al análisis de las entrevistas, que han sido transcritas íntegramente ${ }^{13}$, aquí se ha optado por una perspectiva temática ${ }^{14}$, realizada con la ayuda de ATLAS-TI ${ }^{15}$, un programa diseñado especialmente para el análisis textual. La perspectiva temática, supone que renunciamos a intentar encontrar un significado o sentido a cada una de las 26 biografías (de biografías múltiples) recogidas, y en su lugar, tomamos en cuenta elementos significativos del conjunto de discursos en diferentes aspectos y los sumamos, los integramos. El objetivo es doble. Por una parte, se trata de identificar los criterios de definición de la, más o menos

${ }^{13}$ Como agradecimiento a su colaboración la transcripción completa de la entrevista ha sido entregada a cada uno de las personas entrevistadas.

${ }^{14}$ Ver Blanchet y Gotman (1992).

${ }^{15}$ Aquí agradezco el empeño de Laia Ferrer, que en sus funciones de técnica-investigadora del proyecto, insistió en la utilización de este programa, en aras a las ventajas de su sistema de codificación. Así, mi conocimiento directo de las 26 biografías, por haberlas realizado personalmente, puede ser ordenado y presentado de forma más sistemática. 
compleja, constelación de relaciones familiares y afectivas (re)construida en el momento de la entrevista. Esto es, comprender cuál es la naturaleza de la relación afectiva de la persona entrevistada con las personas que ella considera más cercanas, con las que tiene una relación familiar (hijos, parejas, padres, hermanos...) o no (amigos, compañeros, colegas...); y por otra parte, desvelar los factores explicativos, o más bien relacionados, con la biografía familiar, y en particular con el proceso de ruptura y post-ruptura de la unión. De esta manera, las narraciones permiten conocer la importancia que los biógrafos atribuyen a los acontecimientos que jalonan sus biografías (la familiar y las relacionadas), identificar nudos biográficos, es decir aquellos hechos que marcan un antes y un después en el curso de vida, y dar sentido a la superposición de biografías múltiples que definen tiempos con ritmos diferentes que se interrelacionan entre si y tiñen con una tonalidad diferente cada etapa de la vida. En esta tarea, el análisis del material gráfico es crucial.

En este análisis, los dos ejes analíticos, familia y género, son transversales y aparecen de forma continua a lo largo de las narraciones, por invitación expresa de quién impulsa el monólogo, y por el hecho de que el propio entrevistado se sumerge en su biografía emocional poniendo luz y sombra en diferentes pasos de su propia trayectoria, haciendo, muy a menudo, referencia expresa a la trayectoria paralela de su ex -cónyuge.

\section{RESUlTAdOS ACERCA DEL PROCESO, LAS BIOGRAFÍAS Y LAS FAMILIAS}

A continuación presento unas primeras reflexiones que emergen de las narraciones y del material gráfico recogido (diagramas y líneas de vida) en relación con tres puntos: el proceso de ruptura de los vínculos afectivos; las biografías que son relevantes en esta etapa post-divorcio; y la configuración de relaciones familiares y afectivas, en el momento de la entrevista. Tres temas que pueden ser de interés para el análisis de las biografías familiares y otras biografías relacionadas.

El argumento principal es que la familia no es un sustantivo, sino un verbo, es decir, que su configuración se reconstruye de forma permanente a lo largo de la vida de los individuos, y que el divorcio es un punto de inflexión en la biografía individual que impulsa cambios no sólo en la biografía familiar sino en diferentes dimensiones vitales. Por tratarse de la ruptura de uniones con hijos, se espera y se constata, una gran centralidad de los hijos tanto en la percepción de la propia familia como en las múltiples biografías que siguen al pos-divorcio. 
Cabe recordar, que la muestra tiene un perfil muy particular, por su edad y grupo social de pertenencia. Se trata de personas que se han hecho adultas en un período histórico de la España de apertura, y de cambio social y familiar notable. Que las invitamos a contar su historia de vida cuando ya son adultas, que nos hablan, por ejemplo, de su primera unión, décadas más tarde de que esta aconteciera.

Por último, vale la pena advertir, que entre las personas entrevistadas, a las que se ha llegado por el procedimiento de bola de nieve, únicamente dos mujeres han tenido hijos en el seno de una segunda unión, si bien todos y todas mantienen vínculos muy fuertes con los hijos de la primera unión y prácticamente todos ellos y ellas hablan de nuevas relaciones sentimentales y sexuales, más o menos estables. Ello sugiere, que cuando se transita por nuevas maternidades, y más aún por nuevas paternidades -y quizás se han debilitado los lazos con los hijos de la primera unión- narrar la propia biografía no es una empresa tan atractiva ${ }^{16}$.

\section{La ruptura de una unión, un largo proceso}

Las historias de amor nunca son simples, escribe el demógrafo Philippe Antoine (2009, p. 61) en el capítulo dedicado a las uniones y desuniones del último libro del Grupo de reflexión sobre análisis biográfico del INED ${ }^{17}$ que lleva el sugerente título Estados borrosos y trayectorias complejas. Este es un libro que explora el tratamiento y la interpretación de trayectorias de vida complejas y plantea que los cambios de estado (por ejemplo de tener pareja a no tenerla), no pueden ser reducidos a simples acontecimientos, sino que son transiciones difusas, como lo es el tiempo en el que tienen lugar los acontecimientos que marcan un cambio de estado, y por ende lo son los estados también.

Para ilustrar esta idea, y como acto simbólico de agradecimiento profundo por su colaboración, doy la voz a nuestras biógrafas y biógrafos, indicando al final de cada cita entre paréntesis su seudónimo, año de nacimiento y número de hijos en el momento de la ruptura.

${ }^{16}$ Algunos de los biógrafos han hecho mención de los hombres que no quieren hablar, porque el haber roto el lazo con sus primeros hijos, les causa tanto dolor que no pueden mirar atrás.

${ }^{17}$ Los trabajos de este grupo de reflexión del INED y del CEPED (Centre Population et Développement) de Paris incluyen la perspectiva cuantitativa y cualitativa de las biografías. 
"Hasta que no me casé de nuevo, siete años después de la ruptura, mi ex no entendió que ya no era suya... La crisis había empezado un año después del nacimiento de nuestra hija, yo me voy de casa 3 meses, doce años más tarde él se va de casa por una nueva relación, tercer intento de convivencia con engaño mutuo y después de una crisis terrible de 3 años ruptura definitiva"

(Gradiva, 1955, 1 hija)

"Desde el primer intento de ruptura hasta la ruptura definitiva pasaron 18 años, durante los cuales se produjeron dos separaciones de meses, que llegan a su fin por maniobras de seducción de él. Mi ex no me dejaba ir"

$$
\text { (Ángela, 1951, } 1 \text { hija y } 1 \text { hijo) }
$$

"La intención de adaptarte es tan grande que poco a poco te vas negando. La vida familiar era dura. No había alegría. Yo quería una relación más profunda. Durante 5 años luché para que funcionara la relación, chocábamos continuamente,... me enamoré y me apunté a una pasión, dejé de luchar"

(Eva, 1947, 2 hijos)

"Te casas para toda la vida aunque te divorcies. Yo me separé porque me enamoré, pero la crisis post divorcio no terminó hasta que él tuvo una nueva pareja dos años más tarde"

(Sol, 1961, 1 hijo)

"Después de 18 años de casada,... yo muy dedicada a los hijos, él se va con una chica de 25 años, al cabo de tres años vuelve, se había equivocado, yo lo quería pero después de esta primera ruptura ya no fue lo mismo... 4 años más tarde se produce la ruptura definitiva"

$$
\text { (Cristina, 1956, } 3 \text { hijos y } 1 \text { hija) }
$$

"Novios desde los 15 años, éramos como hermanos, después de tres o cuatro años tormentosos la ruptura se produce para evitar el masoquismo, yo no quería separarme, la primera sorprendida fui yo, yo me consideraba muy tradicional. A pesar de perder la vida cotidiana, fue un alivio, tentaciones de volver: ¡nunca!”

$$
\text { (Julia, 1958, } 1 \text { hijo) }
$$

"La crisis dura unos diez años. La pareja era como un pozo. 7 meses después del nacimiento de nuestro hijo el plantea la separación. Tres años más tarde él se va de casa"

(Paulina, 1957, 1 hijo)

"Viví diez años de casada engañada y contenta. Él era un mentiroso compulsivo. Las infidelidades eran continuas. Me enteré por la llamada de una amante. Nos separamos 4 años después del nacimiento de nuestra hija. La crisis intensa duró casi cuatro años"

(María, 1953, 1 hija) 
"Me casé embarazada, enamoradísima, la crisis empezó dos meses más tarde. Me pasé 10 años intentando salvar la relación, y los últimos 5 sin relaciones sexuales"

(Alejandra, 1966, 1 hijo)

"Estando yo embarazada de mi hija el se va de casa, parí sin el padre, apareció al cabo de dos días. Después de otros 8 años de relación difícil, estaba en casa pero hacia su vida, se produce la separación definitiva, y después vinieron tres años de duelo"

(Nor, 1952, 1 hijo y 1 hija)

"Me casé, a los dos años nació mi hija, y cuando ella tenía un año nos abandonó a las dos. Hace 15 años que no sabemos de él."

(Scarlet, 1968, 1 hija)

"Con el embarazo de mi segundo hijo se inició la crisis. Fueron dos años y medio de crisis tremenda. Con la separación gané la vida, gané la luz. Pero para nuestra crisis no terminó hasta que se casó 12 años más tarde con la "santa" Lucía"

$$
\text { (Marta, 1962, } 1 \text { hija y } 1 \text { hijo) }
$$

"Después de un año tremendo se produjo una separación civilizada y pensada, yo tenía ganas de ver como sería mi vida sola, a pesar de que separar el equipo familiar ha sido el dolor más grande. Hoy, 11 años más tarde, todavía no hemos hecho el divorcio. El vínculo no está roto".

(Isadora, 1956, 1 hija y 1 hijo)

"El vínculo afectivo, pasivo, se inició a mis 21 años, y hasta hoy, con breves períodos de convivencia y rupturas sucesivas,... se mantiene"

(Pedro, 1965, 1 hija)

"Ella era mi novia desde los 17 años, antes de la ruptura vivimos 3 largos años de crisis,..."

(Luís, 1964, 1 hija)

"Yo me casé para toda la vida, después de dos años de crisis, me marché de casa sin nada"

(Andreu, 1956, 2 hijas)

"La ruptura se produjo después de dos años en los que ella estuvo prácticamente ausente, estaba cansada de mi, ... ella se enamoró de un viejo amigo, fue una fatalidad según ella"

(Patrick, 1960, 3 hijas) 
"Nuestra relación era un narcisismo a dos, no había amor, aunque aparentemente todo era perfecto, el niño siempre estaba atendido. Después de un año y medio de desencuentro total yo me fui, nos separamos"

(Manuel, 1960, 1 hijo)

"Después de 7 años de crisis sexual... ella me rechazaba sexualmente cada tres días, hacíamos el amor una vez al mes,... no podía soportarlo más, conflicto de sentimientos, me fui"

(Mimo, 1956, 1 hijo)

"Ella se desenamoró de mi. Tenía otra pareja. Nos separamos. Dos años más tarde nos divorciamos. La ruptura definitiva del vinculo ha venido poco a poco"

(Eudald, 1952, 2 hijas)

"Desde el nacimiento de nuestra hija, durante cuatro años, la vida cotidiana era un colapso, nada iba bien, todo era negativo... la situación me estaba anulando, la separación fue una liberación"

(Bruce, 1954, 1 hija)

"La crisis se inicia con el nacimiento de nuestra primera hija, la madre la rechazaba,... vivimos 8 años de duelo, con breves períodos buenos, nace la segunda hija,... ella estaba cansada de mi, me tenía abandonado, yo me estaba volviendo loco, no era yo. Nunca pensé que iba a separarme algún día, yo soy un hombre de familia. No he dejado de quererla"

$$
\text { (Pol, 1964, } 1 \text { hija y } 1 \text { hijo) }
$$

"Ella tiene una enfermedad mental. La crisis pre-divorcio duró 6 años,... mi padre me decía "si no te gusta tu mujer te aguantas, es la madre de tu hija"... me fui porque ella me echó de casa, quince días después me convertí"

(Joan, 1955, 1 hija)

"Me casé poco enamorado, el matrimonio no era la felicidad. Yo estaba entregado a mi profesión. Nació nuestro hijo. Nos separamos al poco tiempo. La familia no funcionaba. El período post: dos años muy traumáticos, la sensación de haber fallado en el matrimonio no en la paternidad. No ha habido ni un solo día que pensara que no debía haberme separado"

$$
\text { (Juan Miguel, 1958, } 1 \text { hijo) }
$$

"Al saber que ella tenía otra relación se me cayó el mundo encima. La ruptura fue instantánea y en cierto sentido definitiva,... pero desde entonces llevamos 6 años de lucha materialista"

(Tomi, 1956, 1 hijo) 
"Han sido diez años de relación difícil. Desde el primer beso. El nacimiento de nuestra hija fue un momento trágico. Después de la ruptura momentos de tristeza profunda por el alejamiento de mi hija"

(David, 1955, 1 hija)

La muerte es lo único en la vida que viene de un solo golpe ${ }^{18}$, dice un refrán. Excepto en el caso de viudedad, el acontecimiento que marca la salida de una unión es muy difícil de establecer con precisión. La separación, dejar de estar unido, es un largo proceso compuesto de múltiples acontecimientos: la degradación de las relaciones de pareja, las vidas paralelas, la ausencia de relaciones sexuales y las camas separadas, la intervención de la familia y de las personas más próximas, la separación de hecho y la residencia en casas diferentes, la negociación del cuidado de los niños, la separación de bienes, los procesos judiciales, etc.

En las historias de amor y desamor, según el testimonio de nuestros 26 biógrafos y biógrafas, ni las transiciones ni los estados son nítidos. La separación es un largo proceso en el que los vínculos afectivos entre las dos personas van debilitándose, las prácticas amorosas se transforman, y en todos los casos el proceso de ruptura empieza mucho antes de la separación física de los cónyuges y puede que se prolongue hasta mucho después de ésta.

Al trazar la línea de vida, para ubicar los acontecimientos clave de este proceso de ruptura, se observa que el proceso de ruptura vivido como un período de crisis, adopta en cada biografía una forma e intensidad diferente. En unos casos constituye un proceso discontinuo, con diversas rupturas temporales, y en otros casos, la crisis se asienta de una sola y definitiva vez.

Cuando el proceso es muy largo, se producen transiciones, cambios de estado que tienen vuelta atrás; por ejemplo, separaciones de residencia temporales. La argumentación de los actores es que no hay acuerdo entre los cónyuges respecto a la decisión de separarse, circunstancia que da lugar a una serie de estrategias que mantienen la relación en una situación aparentemente estancada, mientras que una insatisfacción latente se manifiesta esporádicamente por los estallidos que brotan una y otra vez. La voz de Ángela ilustra este primer modelo. Ángela explica que las maniobras de seducción estaban impregnadas de amenazas respecto a la relación con los hi-

18 E incluso, en la actualidad, esto es discutible, pues la viudedad, por efecto del alargamiento de la vida, puede llegar por una muerte que ya fue anunciada por un largo período de enfermedad. 
jos. En este caso, ante el binomio insatisfacción-responsabilidad maternal, la responsabilidad gana la partida.

Por otra parte, entre las modalidades de crisis continua nos encontramos con uno de los factores que aparece reiteradamente como factor "determinante" del divorcio: una unión a temprana edad. Es el caso de Alejandra, que se casó con 18 años, y la crisis duró tanto como la misma unión. En ocasiones el matrimonio sobreviene sin haberlo decidido de forma consciente y más tarde llega un momento en el que se cae en la cuenta de que a dicha relación le falta algo esencial. Es el caso de Julia, y también el de Juan Miguel.

Una modalidad distinta de crisis, continua e intensa, se da cuando después de un largo período de convivencia sin cuestionamientos, la persona descubre que está en una situación que no responde a los deseos de su fuero interno. En ocasiones, nuestras biógrafas y biógrafos, pueden identificar un factor desencadenante claro, como en el caso de Eva: una pasión; otras veces la decisión de romper proviene de una situación crónica: insufrible, sin sentido, sin amor, en el que el interés por la otra persona ya no está, y uno o una empieza a no reconocerse a sí misma.

Para las mujeres, a menudo, la separación física comporta una ruptura definitiva de los vínculos afectivos. El padre de sus hijos es una persona a la que en general se le quiere bien, pero con la que ya no hay nada. Para los hombres, a veces, la ruptura definitiva del vínculo no se produce nunca. Es una mezcla de sentido de responsabilidad, de protección, de derecho a gestionar la vida de la otra y de propiedad. Incluso en el caso de haber iniciado otra relación afectiva, en ocasiones les resulta difícil renunciar a su rol anterior. Pero este sentimiento de pertenencia también puede formularse en femenino: "me divorcio de ti, pero eres mío".

\section{Biografía familiar y biografías vinculadas}

En nuestros estudios anteriores sobre los determinantes del divorcio, construíamos modelos explicativos en los que el divorcio era la variable dependiente y las otras circunstancias (laborales, educacionales, y residenciales) eran las biografías que determinaban la biografía familiar (ver una síntesis de nuestros resultados en Solsona y Simó, 2007). En este estudio cualitativo, vemos también lo que pasa en la etapa que se inicia después.

El divorcio es un nudo biográfico, un punto de inflexión clave que divide la vida en dos partes. Así lo sienten nuestras biógrafas y biógrafos. Es el final 
de una etapa y el anuncio de una nueva ${ }^{19}$. Es una profunda crisis, y a la vez una gran oportunidad. En palabras de Cristina "Ha sido el golpe más fuerte que he recibido en mi vida y creo que el mayor impulso". El divorcio no es solo el resultado de, sino un impulso para. Un impulso para innovar en el ámbito profesional, para iniciar unos estudios que siempre se habían querido realizar y estaban allí aparcados, para cuidar de sí mismo o de sí misma, de buscar una relación sexual satisfactoria, para realizar un viaje aplazado en diversas ocasiones o para luchar hasta conseguir la casa de los sueños. También por supuesto, para tener una nueva pareja y/o para tener más hijos, para expandir o ampliar la propia familia o para construir una nueva.

Ya he dicho más arriba, que con las líneas de vida, se identifican aquellos acontecimientos relatados por las personas entrevistadas que son elementos claves de su biografía familiar (nuevas uniones, nuevos hijos, etc.), así como eventos de otras dimensiones vitales con las que se pueden establecer relaciones de asociación o causalidad, entre los que se cuentan el trabajo, los estudios, los cambios residenciales; y también con otros acontecimientos (no contemplados en las encuestas de tres o cuatro biografías) en los que me voy a centrar en los próximos párrafos.

Entre las biografías relacionadas, la centralidad de los hijos en la vida de los divorciados y las divorciadas es evidente. Prácticamente, todo cuanto acontece por decisión propia en la vida está mediatizado por las necesidades y las experiencias de los hijos, sobre todo durante su infancia y adolescencia. Así por ejemplo, la decisión de constituir una nueva unión, puede quedar aplazada o simplemente descartada por dar absoluta prioridad a los hijos. No se renuncia a tener relaciones sentimentales estables, pero si a formar una nueva unidad residencial común. En el caso de los hombres, que no residen de forma habitual con sus hijos esta opción es todavía más común.

A través de la relación con los hijos, o independientemente de esta relación, la trayectoria de la ex-pareja también está muy presente en las narraciones de nuestros biógrafos. Esta presencia adopta diferente tonos: comparación, rivalidad, vigilancia o bien respeto, cariño y acompañamiento.

En segundo lugar, aparece la biografía de la salud, que como sabemos suele ser una prioridad en la vida de todos. Puede tratarse de la salud de ego, la salud de los hijos, la salud de los padres o la salud de la ex-pareja. Cuando se

${ }^{19}$ Caroline Laborde, Eva Lelièvre y Géraldine Vivier, (2007, p. 572) a partir de la encuesta "Biographies et entourage", encuentran que estar divorciado (o viudo), sobre todo para los hombres, aumenta la probabilidad de articular la vida en un número de períodos biográficos superior a la media, contrariamente al hecho de estar casado. 
trata de la propia salud, se habla de salud física, emocional, mental y espiritual. Se pone de manifiesto que una vulnerabilidad subyacente en todos los seres humanos se activa en esta situación de crisis, y conviene cuidarse para evitar daños mayores. Esta vulnerabilidad tiene una expresión más fuerte entre los hombres, por haber vivido experiencias de exclusión, durante el matrimonio (sexuales) y en la etapa posterior al divorcio (difícil contacto con los hijos), nunca antes imaginadas. Por ejemplo, Tomi dice "hay personas a las que se les va la cabeza, y no me extraña en absoluto". Pero a menudo se buscan recursos para comprender mejor el proceso de ruptura y adquirir herramientas para afrontarlo, en forma de terapias o de grupos de ayuda mutua.

En tercer lugar, aparecen las historias de amor y la sexualidad, como historias independientes de la biografía familiar formada por relaciones de pareja que se formalizan y se socializan dentro del grupo de personas más cercanas, y forman parte de la intimidad compartida. Las historias de amor no se comparten, pertenecen a la intimidad privada, en muy diversas acepciones: como forma de satisfacer las necesidades afectivas, como forma de luchar contra el aislamiento, como algo natural de la vida ${ }^{20}$.

Por último, y en cierta forma relacionada con la anterior, después de una ruptura de unión, algunas personas, hombres y mujeres, dan mucha importancia a preservar un espacio propio, un espacio absolutamente privado, razón por la cual, a pesar de mantener relaciones sentimentales y sexuales estables no dan el paso, de forma consciente y deliberada, a compartir el mismo techo. Este espacio absolutamente privado puede ubicarse en el hogar que se comparte con los hijos, de forma permanente o esporádica, pero en cualquier caso, su colonización está vetada a esta nueva pareja afectiva.

\section{Después del divorcio, una familia más amplia}

Después de una ruptura de unión las formas familiares se diversifican, su tamaño se amplia con parientes consanguíneos, políticos y amigos fieles ${ }^{21}$, que cumplen el papel de hermanos o hermanas ${ }^{22}$, de manera que el entramado de vínculos afectivos y familiares deviene más complejo.

\footnotetext{
20 Sobre la transformación de la intimidad ver Anthony Giddens (1992).

${ }^{21}$ Ketokivi, Kaisa (2008, p. 255) también considera el papel de la amistad en la reconfiguración familiar postdivorcio.

22 Por analogia al rol fraternal, cito de nuevo a Eva Lelièvre y Geraldine Vivier (2006, p. 193) con datos de la encuesta "Biographies et entourage": un 20\% de los entrevistados asignan un rol parental a una persona, diferente a los padres biológicos, antes de los 15 años de edad.
} 
Respecto a la diversidad, conviene recordar que tanto en las reflexiones ya clásicas de Levi- Strauss (1956) como en los estudios más recientes sobre las formas de vivir en familia (Gittins, 1992; Brullet, 2007 y 2008) se constata que la pluralidad de formas es el único trazo común a cualquier estudio etnográfico sobre la familia. Levi Strauss escribió: "El mismo hecho de que varíe incesantemente de sociedad en sociedad muestra que, en lo referente a la familia, es el mero hecho de su existencia lo que es misteriosamente necesario, mientras que la forma bajo la que aparece no es en manera alguna importante, por lo menos desde el punto de vista de cualquier necesidad natural"(Levi Strauss, 1974, p. 32).

Nada más empezar la entrevista, pedimos a nuestros entrevistados, que nos hablen de su propia familia. Una pregunta, que como ya he comentado más arriba, causa sorpresa, porque no existe una respuesta esperada. Incluso cuando el entrevistado demanda "¿qué familia? ¿la de origen? ¿la creada?", la respuesta de la entrevistadora es "precisamente lo que buscamos en esta investigación es conocer como las persona definen su familia". Y lo que está claro, a tenor de dicha reacción, es que la familia no responde a ninguna identidad real predeterminada. La familia se redefine en cada momento, y cada persona la percibe en función de los acontecimientos que dan sentido a su biografía, y en este sentido el divorcio es un acontecimiento determinante muy importante. Algunas personas entrevistadas han expresado que si se les hubiera formulado esta pregunta antes de la ruptura no tendrían dudas en contestar "mi familia es mi pequeña familia, mi pareja y mis hijos". En el post-divorcio, nuestros biógrafos y biógrafas definen su propia familia apelando a vínculos de sangre o políticos (mi familia, la familia de mis hijos), vínculos de convivencia o no (quien vive en el hogar) y/o de afinidad y de amor (familia de elección).

En sus respuestas, los vínculos de sangre ascendentes y descendentes, pueden alcanzar solamente dos generaciones (yo y mis hijos), tres (padre, madre, o padres, yo y mis hijos), o cuatro (cuando incluyen a los abuelos); los vínculos colaterales pueden incluir a los hermanos, a los sobrinos y sobrinas. En el post-divorcio los hijos son los únicos que indiscutiblemente siempre forman parte de la propia familia. Para algún entrevistado incluso son más que familia, "mi hija es más que hija, es única en el universo" dice Pedro. Las razones por las cuales se incluyen otros parientes de sangre, ascendentes y descendientes, hacen referencia a la gratitud, a la responsabilidad y al apoyo, por ejemplo "cuidar a la madre en agradecimiento a la vida que me ha sido dada", "son un puerto seguro", "siempre puedes contar con ellos", "los padres y los hijos nunca te fallarán, las parejas son otra cosa" (ver figura 2). Lo cotidiani- 
dad, la convivencia, la complicidad, el apoyo mutuo, son razones para incluir o no a los hermanos, primos y demás parientes colaterales. El caso de los hermanos es singular, son parientes de sangre, están ahí, pero a veces están más lejos que los amigos íntimos; pero se trata de una lejanía relativa, pues en muchos casos es un vínculo que se activa en los momentos de crisis. Nuestros biógrafos y biógrafas hablan de ello. Los tíos y abuelos, pueden ser personas especiales, que han dejado un legado en experiencia de vida, una enseñanza, y que han jugado un rol muy especial.

El divorcio no está reñido con la inclusión de parientes políticos (de la relación anterior) en la propia familia, la ruptura de una unión divide la vida en dos partes diferentes, pero no de la misma manera a la parentela adquirida por el nacimiento de hijos comunes. El bagaje relacional que antes se compartía muy a menudo queda preservado, sobre todo cuando a las relaciones se les había puesto nombre: quién fue tío o tía para su sobrino político sigue siéndolo después de la ruptura.

Este cruce entre vínculos políticos y de sangre indica que se define la propia familia también a partir de la familia del hijo o los hijos ${ }^{23}$. Por ejemplo, en general no se incluye a la ex pareja en la propia familia (aunque también hay excepciones en este sentido), pero sí se incluye a la ex suegra o a los sobrinos del propio ex, es decir a los abuelos de tus hijos y a los primos de tus hijos. Cabe decir que los biógrafos, más que las biógrafas incluyen a su ex entre los miembros de su propia familia, porque "la madre de mis hijos siempre será diferente a cualquier otra mujer, y en este sentido la separación no ha cambiado nada" (Andreu), o porque hay un sentimiento de responsabilidad que va más allá de la convivencia, e incluso de la trayectoria familiar post-divorcio de su ex pareja. Por ejemplo Patrick dice: "si a ella o a su nuevo esposo les ocurriera algo, yo me haría cargo tanto de nuestras hijas comunes, como de la nueva hija de ella".

La familia de elección, entendida como la elegida, no la que te adoptó, tiene también su lugar en la configuración de la propia familia (ver en la figura 1, el ejemplo de Joan Miquel). Aquellas amigas o amigos íntimos, con los que se tiene una relación más estrecha que con los propios hermanos, con los que se han atravesado las pruebas de la vida adulta, también son miembros de la familia amplia. En particular entre las mujeres, pero no sólo entre ellas, las amigas que comparten el trabajo de amar, de cuidar de los hijos, de cuidar de los demás, con las que se comparte secretos, retos, complicidades y vías de creci-

${ }^{23}$ Ann-Maija Castrén (2008, p. 250) encuentra los mismos resultados para Finlandia. 
miento personal, son consideradas las verdaderas hermanas. También, las personas con las que se comparten determinadas prácticas, en un ámbito artístico o espiritual, tienen su espacio en la propia familia. Resultados parecidos se han encontrado en otros países. Las personas con altos niveles de instrucción mantienen redes amplias de amistades y de colegas y cuentan con el apoyo sistemático e intenso de las personas más próximas ${ }^{24}$.

Los biógrafos y biógrafas que tienen trayectorias migratorias de más larga distancia (han vivido su infancia y primera adolescencia en América, o en otro país europeo) son quienes dibujan un mundo de constelaciones familiares más amplio, incluyendo parientes por razón de sangre, política o elección, quizás porque su cuna no está aquí y hay que invocar a los ancestros o hermanarse con los iguales para sentir que la vida en familia es, es decir, que existe también para él o para ella. La familia, en pocas ocasiones es nuclear, si bien más de uno dice que lo era antes del divorcio. Algunos entrevistados hablan en términos de tribu. Cabe preguntarse si este rasgo común de este colectivo que ha protagonizado un divorcio, de no limitar sus relaciones a la familia de sangre, es exclusivo de ellos, o bien, vivir en tribu más o menos explícita es y ha sido lo habitual, o bien, si estamos asistiendo al fin de la excepción nuclear.

Para terminar, subrayar que familia y co-residencia no son conceptos equivalentes, y viceversa co-residencia y familia, tampoco lo son. La propia familia no se circunscribe a un hogar específico. Así, en demografía de la familia, la utilidad del hogar como artificio para aproximarnos a las relaciones familiares, en este escenario post-divorcio pierde su sentido ${ }^{25}$. Vivir solo no significa no tener familia, ni relaciones de pareja estables, ni vínculos afectivos fuertes. La familia, la sexualidad y la afectividad a menudo se encuentran fuera de las fronteras del propio hogar. Uno o una puede residir en un hogar unipersonal durante algunos días de la semana que se convierte en monoparental en ocasiones, ciertos fines de semana, por ejemplo, cuando el hijo o hija viene a residir con su padre o madre. Por otra parte, vivir bajo el mismo techo tampoco da un derecho inmediato de pertenecer a la familia del otro, ni siquiera viviendo en pareja. Sólo para dar un ejemplo: Alejandra percibe que su familia está formada por sus padres, sus dos hijos, uno de la pareja anterior y otro de

\footnotetext{
${ }^{24}$ Ver por ejemplo Claude Martin (1991) para el caso francés.

25 Estos resultados, son una constatación más de las agudas reflexiones del demógrafo Hervé Le Bras (2003) cuando dice que la familia no se deja constituir como objeto de estudio, y que las tentativas de explicar el comportamiento humano que se construyen a partir de ella corren el riego siempre de confundir los índices estadísticos ad hoc con las verdaderas causas.
} 
la pareja actual, pero la pareja actual, aunque es padre de sus hijos no lo siente como familia "es otra cosa".

\section{CONCLUSIONES ABIERTAS}

La constitución y disolución de una unión es un buen ejemplo de la borrosidad de los estados y las transiciones, también de la borrosidad del tiempo y del espacio. No es posible dar una datación precisa para la transición del matrimonio al divorcio. Antes y después de la ruptura el matrimonio contiene al divorcio y viceversa. Esta investigación ilustra, tal como afirmó Louis Henry (1993), que el divorcio es una dimensión del matrimonio, y constituye además en sí mismo una institución ${ }^{26}$. La existencia de hijos antes de la ruptura impide hablar de la disolución de la familia ${ }^{27}$. Los hijos, en la post ruptura se convierten en el núcleo que modela la nueva configuración de relaciones familiares y afectivas, y mediatiza las decisiones respecto a la constitución de nuevas uniones.

Por tanto, quedan sin respuesta precisa algunas preguntas: ¿Cuándo empieza la ruptura? ¿Es posible hablar de un final de proceso? ¿Puede establecerse un momento en el que el vínculo afectivo con la ex-pareja se ha roto definitivamente? Y si la ruptura de este vínculo es tan difícil de aprehender cuando ha habido hijos, hablar de las causas o de los factores determinantes resulta todavía más especulativo. Se pueden distinguir ciertos factores desencadenantes, pero no factores determinantes. Sin embargo, tal como se evidencia en el análisis textual, se puede afirmar que la causa última que mueve a toda persona que inicia una separación, es probablemente volver a ser uno mismo, después de un período de crisis en el que se produce un cuestionamiento de la propia identidad. Este estudio muestra que el divorcio más que ser el resultado de cambios en las biografías laborales, educativos y residenciales, es el inicio de una nueva etapa en la biografía individual que impulsa mutaciones en biografías habitualmente no observadas, en las encuestas biográficas, que tienen que ver con la salud, el amor, los viajes y una habitación propia, entre otros.

\footnotetext{
${ }^{26}$ Ver el trabajo pionero de la socióloga Christine Delphy (1982) en el que afirma que revela la autentica naturaleza del matrimonio.

${ }^{27}$ La jurista Montserrat Tur (2007, p. 53) afirma "Más allá de la relación matrimonial o de pareja, que legalmente puede quedar extinguida, la presencia de hijos e hijas impide que la familia que padece una ruptura, deje de ser a los ojos del derecho, una familia".
} 
Los hijos constituyen el núcleo de la redefinición de los vínculos familiares y efectivos. Para definir la propia familia el único vínculo sólido es la familia creada: la maternidad y la paternidad son el vínculo prioritario. El resto de relaciones, siguiendo la expresión de Bauman, son más líquidas ${ }^{28}$ y se modifican a lo largo de la vida, sin criterios previos, en un proceso de construcción permanente, en el que los hechos y las percepciones se influyen mutuamente. Las redes de parentesco biológico están ahí, a veces en reposo, a veces activadas. Un hermano puede percibirse como no formando parte de la propia familia, y una amiga intima puede ser la verdadera hermana. Con el divorcio uno no se divorcia necesariamente de la familia política, los vínculos que tienen nombre son difíciles de disolver.

Y los hijos a veces viven en diferentes espacios, de ahí la borrosidad del espacio que empapa también a otras relaciones. Las nuevas relaciones de pareja, el amor y la sexualidad, a menudo tienen lugar fuera de las fronteras palpables del hogar y de la familia. El análisis biográfico, por configurar la línea de las transiciones vitales y determinar el orden y las causas de los acontecimientos, ha priorizado el tiempo. Las narraciones de nuestras biógrafas y nuestros biógrafos muestran que la vida familiar, con parientes de sangre, políticos y de elección, tiene lugar en espacios diversos. Para avanzar en el conocimiento sobre las transformaciones de los vínculos afectivos y familiares es preciso ir más allá del concepto-artificio de familia-hogar, buscar la intersección entre el tiempo y el espacio.

Recibido: 29/06/2009

Aceptado:25/09/2009

${ }^{28}$ Ver Zygmunt Bauman (2003).

Estudios Geográficos, Vol. LXX, 267, pp. 633-660, julio-diciembre 2009 ISSN: 0014-1496, eISSN: 1988-8546, doi: 10.3989/estgeogr.0467 
FIGURA 1

EJEMPLO DE CONFIGURACIÓN FAMILIAR EN EL MOMENTO DE LA ENTREVISTA. JOAN MIQUEL

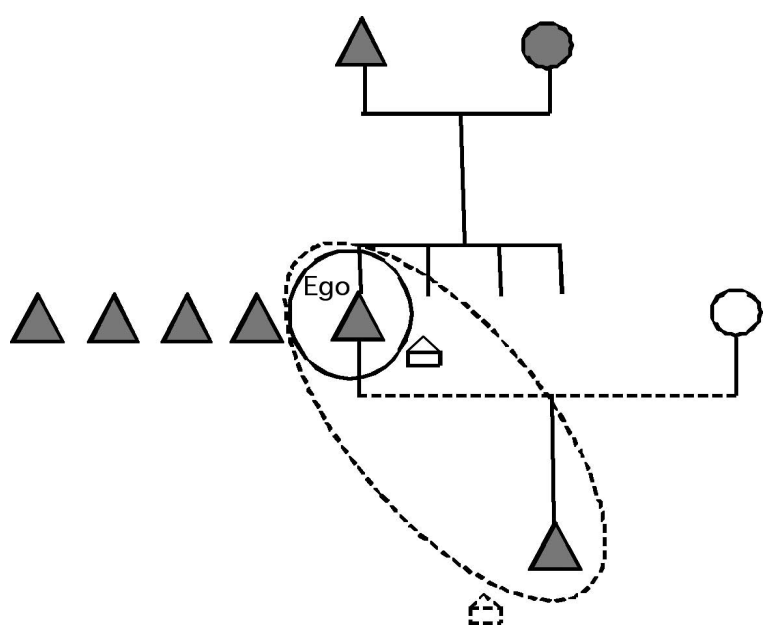

Familia: biológica y amigos. Hogar unipersonal y monoparental en fin de semana.

FIGURA 2

EJEMPLO DE CONFIGURACIÓN FAMILIAR EN EL MOMENTO DE LA ENTREVISTA. ALEJANDRA

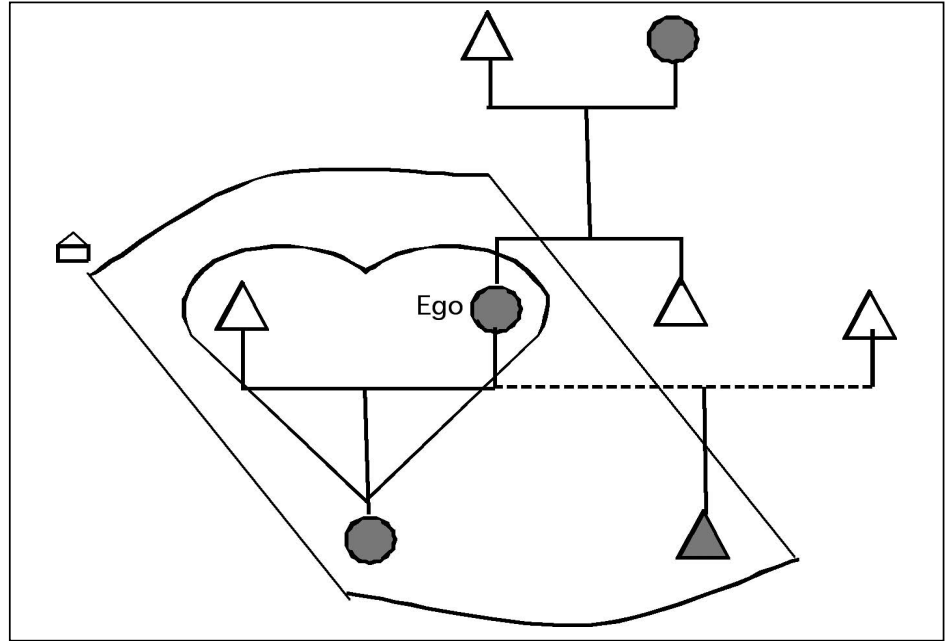

Familia: vínculos biológicos, ascendentes y descendientes. Hogar: vive con la pareja y sus hijos de las dos uniones.

Estudios Geográficos, Vol. LXX, 267, pp. 633-660, julio-diciembre 2009 ISSN: 0014-1496, eISSN: 1988-8546, doi: 10.3989/estgeogr.0467 
FIGURA 3

EJEMPLO DE DISEÑO DE LA BIOGRAFÍA FAMILIAR Y LAS BIOGRAFÍAS VINCULADAS EN LÍNEAS DE VIDA

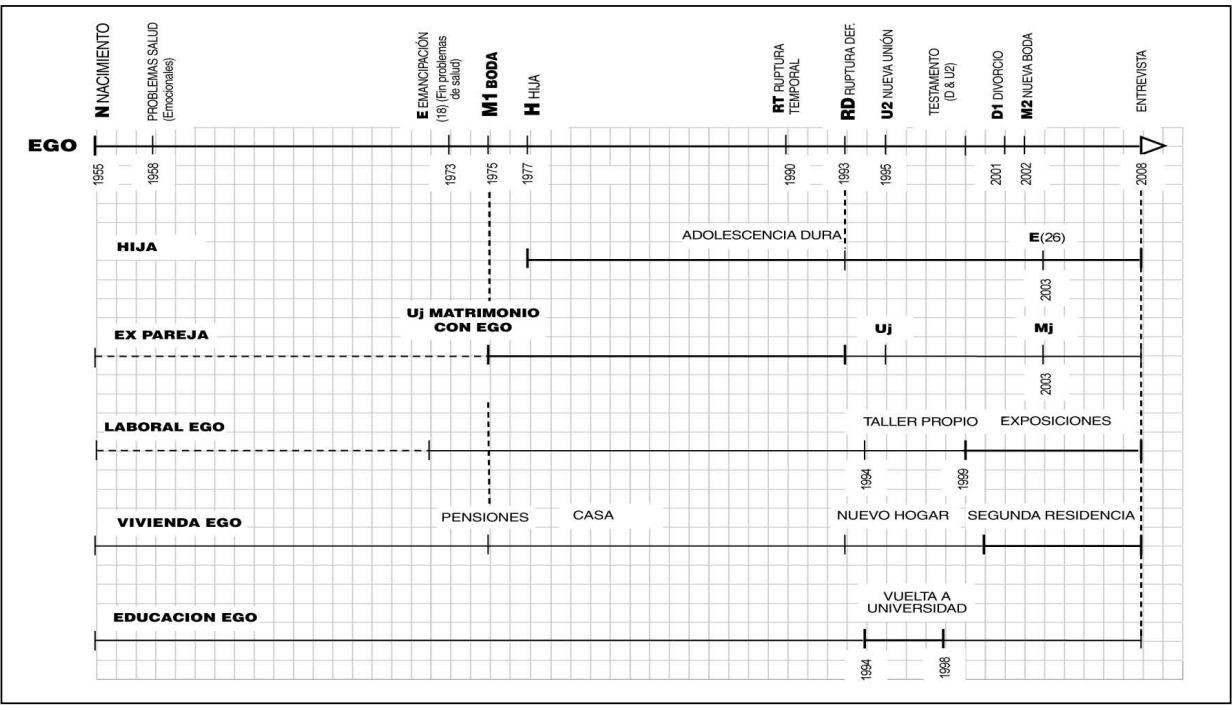

BIBLIOGRAFÍA

Philippe, A. y Lelievre, E. (2006): "Qui est flou: la temporalité, l'événement ou l'état?" a Groupe de réflexion su l'approche biographique (2006), Etats flous et trajectoires complexes, INED, Méthodes et savoirs, $\mathrm{n}^{\circ}$ 5, pp. 25-28.

Philippe, A. et al. (2006): "Unions et désunions: les histoires d'amour ne sont jamais simples!" a Groupe de réflexion su l'approche biographique (2006), Etats flous et trajectoires complexes, INED, Méthodes et savoirs, n 5, pp. 61-86.

Bry, X. y Phillipe, A. (2004): "Explorer l'explicatif: application à l'analyse biographique" Population-F, vol. 59 n 6, pp. 909-945.

Bauman, Z. (2003): Amor líquido. Acerca de la fragilidad de los vínculos humanos, Madrid: Fondo de Cultura Económica.

Blanchet, A. y Gotman, A. (1992): L'Enquête et ses méthodes: l'entretien, Nathan Université, Sociologie 128.

Brullet, C. (2007): "Transformacions familiars, cura dels infants i polítiques públiques", Reflexions Jornades de la Infància. Famílies que eduquen, CIIMU, Institut d'Infancia i Món Urbà, Barcelona, pp. 53-54.

Brullet, C. (2008): "Vida quotidiana i la cura dels altres: afrontar el canvi i la complexitat familiar", Borja de Riquer (Dtor.) Història, Política, Societat i Cultura dels Països Catalans, Barcelona, Enciclopèdia Catalana-Edicions 62. 
Castrén, A.-M. (2008): "Post-Divorce Family Configuration" in Widmer, E. D. y Jallinoja, R. (eds.) Beyond the Nuclear Family: Families in a Configurational Perspective, Bern, Peter Lang, Population, Family and Society, vol. 9, pp. 233-254.

Courgeau, D. (1985): "Bases théoriques et modèles pour une enquête sur la biographie familiale professionnelle et migratoire“, Espace Populations sociétés, $\mathrm{n}^{\circ} 1$, pp. 240-247.

Courgeau, D. y Lelievre, E. (1989): Analyse démographique des biographies, Editions de l'Institut National d'Etudes Demographiques, Paris. pp. 1-23.

Delphy, C. (1982): "Matrimonio y divorcio el doble atolladero" a Delphy, Christine (1982), Por un feminismo materialista. El enemigo principal y otros textos, Barcelona, La Sal Edicions de les dones.

Giddens, A. (1992), La transformación de la intimidad. Sexualidad, amor y erotismo en las sociedades modernas, Madrid, Cátedra.

Gittins, D. (1993): The family in question, The Mac Millan pres Ltd., London.

Houle, R., Solsona, M. y Treviño, R. (2006): "Divorcio y trayectorias familiares postruptura ¿un fenómeno nuevo?" en Roigé, Xavier (ed.), La familia en Cataluña. Continuidades y cambios, Barcelona: Icária, pp. 437-470.

Houle, R., Simó, C., Solsona, M. y Treviño, R. (1999): "Análisis biográfico del divorcio en España", Revista Española de Investigaciones Sociologicas n 88 (oct.-dic.), pp. 11-35.

Ketokivi, K. (2008): "Biographical Disruption, the Wonded Self, and the reconfiguration of Significant Others", in Widmer, E. D. y Jallinoja, R. (eds.) Beyond the Nuclear Family: Families in a Configurational Perspective, Bern, Peter Lang, Population, family and Society, vol. 9, pp. 255-278.

Laborde, C., Lelievre, E. y Vivier, G. (2007): "Trajectoires et événements marquants. Comment dire sa vie? Une analyse des faits et des perceptions biographiques", Population-F, 62 (2), pp. 567-586.

Le Bras, H. (2003): "Lillusion familiale" a Marcela Iacub et Patrice Maniglier (Dir.) Famille en scènes Bousculée, réinventée, toujours inattendue, Paris, Éditions Autrement - Collectíon Mutations n 220.

Lelièvre, E. y Vivier, G. (2006): "Les figures parentales dans l'enquête «Biographies et entourage»", in AIDELF (Association international des démographes de langue française), Enfants d'aujourd'hui diversité des contextes, pluralité des parcours, Paris, Presse Universitaires de France.

Levi-Strauss, C. (1974): "La familia", a Polémica sobre el origen y la universalidad de la familia, Barcelona, Cuadernos ANAGRAMA, original: Levi-Strauss, Claude (1956) "Family" en Harry L. Shapiro (ed.) Man, Culture and Society, Oxford University Press, New York.

Martin, C. (1994): "Diversité des trajectoires post-désunion. Entre le risque de solitude, la défense de son autonomie et la recomposition familiale". Population, 6, pp. 1.557-1.583. 
Roussel, L. (1993): "Sociobiographie du divorce et divorcialité", Population, n 4, pp. 919-938.

Simó, C. y Solsona, M. (2003): "Importancia de la participación laboral como determinante del divorcio en España", Papeles de Geografia 37, pp. 245-259, Universidad de Murcia.

Simó, C. y Solsona, M. (2009, inminente): "El registro estadístico de las rupturas de unión en España: Evaluación e ideas para avanzar desde la demografía” in Papers de Sociologia.

Simó, C. y Spijker, J. (2009): Trayectorias pos divorcio en España y en Europa: análisis de la asimetría de género en la formación de nuevas uniones, comunicación presentada en el V Congrés Català de Sociologia, Universitat Autònoma de Barcelona, 17 de abril.

Simó, C., Spijker, J. y Solsona, M. (2009): Post divorce in Europe. Repartnering, new maternities and paternities, European Network for the sociological and demographic Study of Divorce, 7th conference, University of Antwerp, 25-26 Junio de 2009.

Solsona, M., Ferrer, L., Simó, C. y MacInnes, J. (2007): "Trayectorias familiares después del divorcio. Una revisión de las contribuciones recientes desde la demografía", Documents d'Anàlisi Geogràfica. pp. 217-234.

Solsona, M. y Simó, C. (2007): "Evolución histórica del divorcio en España desde la aprobación de la ley de 1981 hasta la reforma de 2004" in CABRÉ, Anna y Pau Miret (coordinadores): La constitución familiar en España, Fundación BBVA, pp. 245-296.

Solsona, M., Simó, C. y Houle, R. (1999): "Separation and divorce in Spain in the context of the European Community", South European Society y Politics, 4, pp. 195-222.

Treviño, R., Solsona, M., Simo, C. y Houle, R. (2000): "Los determinantes sociodemográficos y familiares de las rupturas de uniones en España: La normalización del fenómeno", Boletín de la Asociacion de Demografia Histórica, XVIII, I, pp. 101-235.

Tur, M. (2007): "Ruptura i recomposició familiar: transicions i compromisos de cura. El dret davant les ruptures familiars" a Reflexions Jornades de la Infància. Famílies que eduquen, CIIMU, Institut d'Infancia i Món Urbà, Barcelona, pp. 53-54.

Widmer, E. D. y Jallinoja, R. (eds.): Beyond the Nuclear Family: Families in a Configurational Perspective, Bern, Peter Lang, Population, family and Society, vol. 9.

\section{RESUMEN}

En este artículo se discuten algunos resultados de un estudio cualitativo sobre las trayectorias familiares que siguen hombres y mujeres que han vivido una ruptura de una unión en la que hubo hijos. Primero se presenta el diseño de la metodología cualitativa y luego se ofrecen algunos resultados del trabajo de campo realizado en áreas metropolitanas de España donde el divorcio tiene una intensidad mayor. Las narraciones de nuestros biógrafos y biógrafas permiten discutir a fondo el significado mutante de la familia y los vínculos afectivos en la llamada moderna sociedad líquida, y revisar de forma crítica tres conceptos básicos del análisis demográfico de las biografías de ruptu- 
ras de unión: familia, la datación de los acontecimientos y los llamados factores determinantes.

Palabras Clave: demografía; biografías; divorcio; genero.

\begin{abstract}
In this article some outcomes of a qualitative study on the familiar trajectories that follow men and women who have experienced a break-up of union in which there were children are discussed. The design of the qualitative methodology is first presented before showing some results of the fieldwork done in metropolitan areas of Spain where the divorce has a greater intensity. The narrations of our biographers allow us to discuss the meaning of the family and the affective ties in the so-called liquid modern society and to review three basic concepts of the demographic analysis of the biographies of union ruptures: family, timing of the events and the determinant factors.
\end{abstract}

KEY WORDS: demography; biographies, divorce, gender.

\title{
RÉSUMÉ
}

Dans cet article on discute quelques résultats d'une étude qualitative sur les trajectoires familiales qu'ils suivent des hommes et des femmes qui ont vécu une rupture d'une union dans laquelle il y a eu des enfants. On présente d'abord la conception de la méthodologie qualitative et on offre ensuite quelques résultats de la recherche effectué dans des secteurs métropolitains de l'Espagne où le divorce a une intensité plus grande. Les narrations de nos biographes permettent d'examiner en profondeur la signification mutant de la famille et les liens affectifs dans la moderne société liquide, et de réviser de manière critique trois concepts de base de l'analyse démographique des biographies de ruptures d'union: famille, datation des événements et facteurs déterminants.

MoTS CLÉS: démographie, biographies, divorce, genre. 